\title{
A DYNAMIC METHODOLOGY ON DETERMINING THE MOST APPROPRIATE DUE DATE ASSIGNMENT MODELS FOR JOB SHOP SCHEDULING
}

\author{
Şerafettin ALPAY \\ Industrial Engineering Department \\ Eskisehir Osmangazi University \\ Eskisehir, TURKEY \\ E-mail: serafettin.alpay@gmail.com
}

\begin{abstract}
In a job shop production system, assigning exact due dates is an important task for scheduling performance. On the other hand, predicting due dates accurately is very difficult because of several decision factors should be considered. Many due date assignment models proposed in the literature but none of them is perfect and can produce the best due dates for all jobs arrived to the dynamic job shop environment. So using more than one due date assignment model for all job set may be reasonable. In this study a dynamic solution methodology for determining the most appropriate due date assignment models for the jobs arrived to the shop to optimize the aimed objective function by considering the related decision factors in a dynamic job shop environment is presented.
\end{abstract}

Keywords: Due Date Assignment, Job Shop, Scheduling, AHP. 


\section{Introduction}

In a dynamic job shop, completion time of a job is affected by many factors related to the job and shop characteristics and predicting the due dates accurately is very difficult (Chang, 1994). In most of practical dynamic job shop cases, based on the past experiences, only one due date assignment model is selected and the same model is used to assign due dates of all jobs arrived to the shop without considering many decision factors. Whereas using more than one due date assignment model for all job set by taking into account available decision factors may be reasonable. On the other hand, because of the nature of real life dynamic job shop cases, it may not be practical to run a decision process for selecting most appropriate due date assignment model for each job by considering those factors. But it is possible to reduce the number of repeating choice decisions by grouping the jobs according to the pre-selected criteria (e.g. number of operations on the jobs, job priorities) into a few groups and running decision process for every group of jobs.

\section{Literature Review}

Due date based scheduling in dynamic manufacturing environments has been commonly studied (Pearn et al.,2007, Joseph and Sridharan, 2011, Eguchi, et al., 2012, Chen and Matis, 2013, Nguyen et al., 2014) and there are many due date assignment models proposed in the literature. They may be classified as static or dynamic models. Some of the static models (e.g. TWK, SLK, NOP) only take account of job characteristics (e.g. processing time, number of operations) while others (e.g. PPW, TWKNJ) also consider shop status information, i.e. information about jobs already in the system. Dynamic models (e.g. JIQ, JIS, DTWK) re-determine job priorities as time changes. Buyurgan and Saygin (2008) present a framework that employs AHP in dynamic manufacturing environments for real-time scheduling and part routing. Yazgan (2011) proposes Fuzzy ANP model to select suitable dispatching rules assuming known due dates in flexible manufacturing systems. Nevertheless, the most related studies consider only one of the due date assignment models and that model is used to assign the due dates for all jobs arrived to the shop.

\section{Objectives}

The aim of this study is to present a solution methodology for dynamically determining the most appropriate due date assignment models for the jobs arrived to the shop to optimize the aimed objective function by considering the related decision factors in a dynamic job shop environment. In the study, assuming the jobs are grouped, an AHP model is proposed to prioritize the due date assignment models available for each group of jobs.

\section{Research Design/Methodology}

As mentioned before there are many due date assignment models available for dynamic job shop scheduling and it is very difficult to select the most appropriate due date model to assign the due dates for the jobs to achieve the aimed scheduling objective. The difficulties come from the fact that many decision factors need to be taken into consideration in such decision processes. Those factors may be related to jobs and/or shops, selected dispatching rules or different scheduling objectives. To increase the 
correctness of job due dates in a dynamic job shop environment, a two phased approach is proposed in this study. In the first step, the jobs are grouped into a few job groups according to the selected criterion or criteria by the decision maker. In the second step, an AHP model is used to prioritize the due date assignment models available for each group of jobs.

\section{Data/Model Analysis}

Figure 1 represents the proposed AHP model.

Figure 1 AHP Model

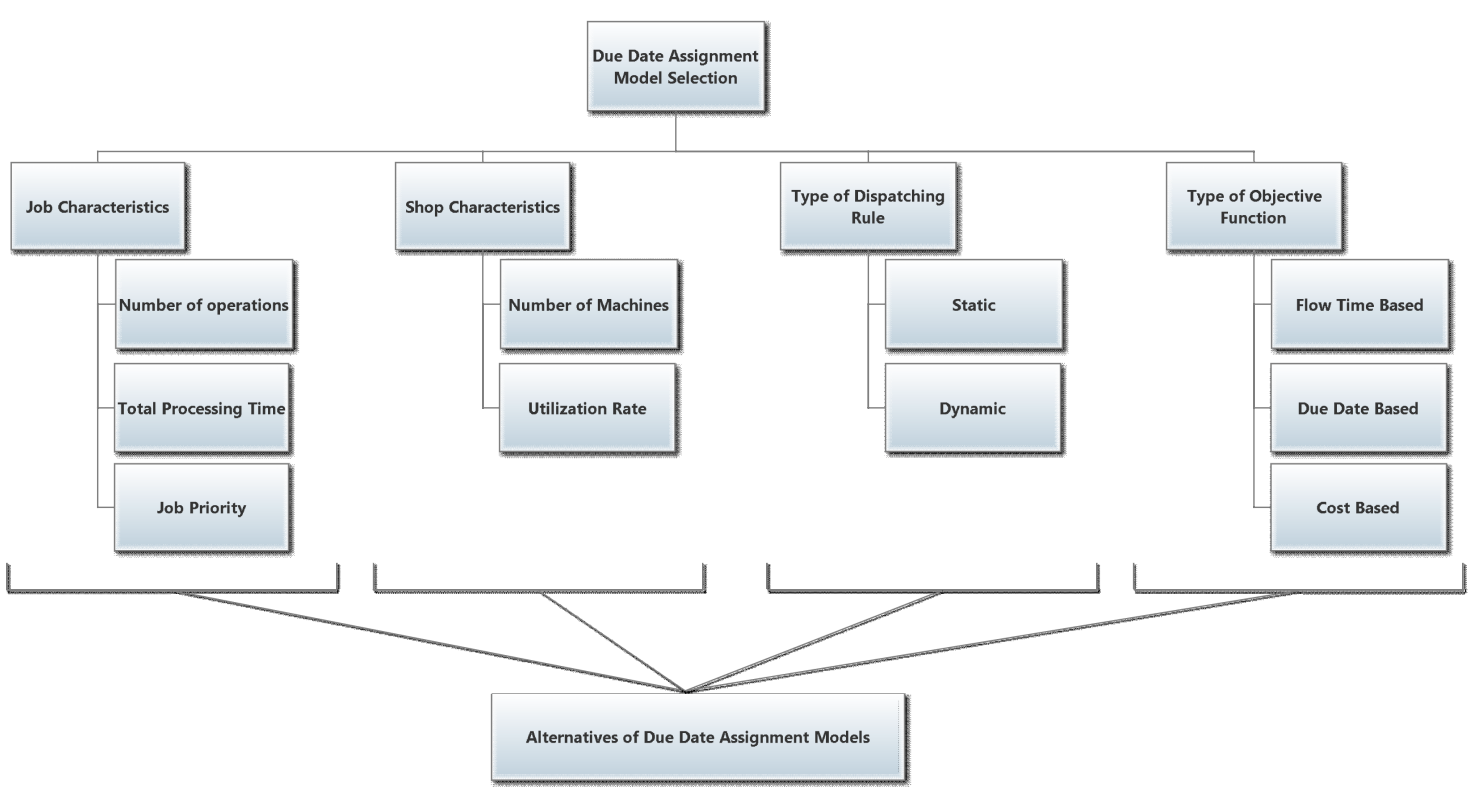

To illustrate the proposed approach, a dynamic job shop environment supplied by Cheng and Jiang (1998) may be used and it is defined as follows; the job shop consists of 5 unique machines. Job arrivals at the shop form a Poisson process and the shop arrival rate is determined by the shop utilization setting. Each job requires one to nine operations, determined randomly according to a uniform probability distribution. Each operation is assigned randomly to one of the nine machines according to a uniform probability distribution, under the constraint that no two successive operations require the same machines. Operation processing times are exponentially distributed with a mean of 1 unit of time. Other assumptions made in this system are; set-up times are included in the processing times, transportation times are excluded, the resources are available continuously, pre-emption of a job is not allowed and processing times of the jobs are known after their arrivals at the shop. The followings are the alternatives of the due date assignment models: $T W K, P P W, D T W K$ and $D P P W$. In the first step, the jobs are grouped into two groups according to the job priorities they have. The first group of jobs has high priorities while the second group of jobs has no any special priorities. In the second step, the overall ratings related to the due date assignment models for each group of jobs are obtained by using the AHP model separately. Figure 2 shows the summary results and the 
IJAHP Article: Mu, Saaty/A Style Guide for Paper Proposals To Be Submitted to the International Symposium of the Analytic Hierarchy Process 2014, Washington D.C., U.S.A.

overall ratings of the due date assignment models for the first group of jobs. Figure 3 presents the sensitivity analysis concerning the first level of the hierarchy.

Figure 2 - Summary results and overall ratings for AHP model

Figure 3 - Sensitivity analysis

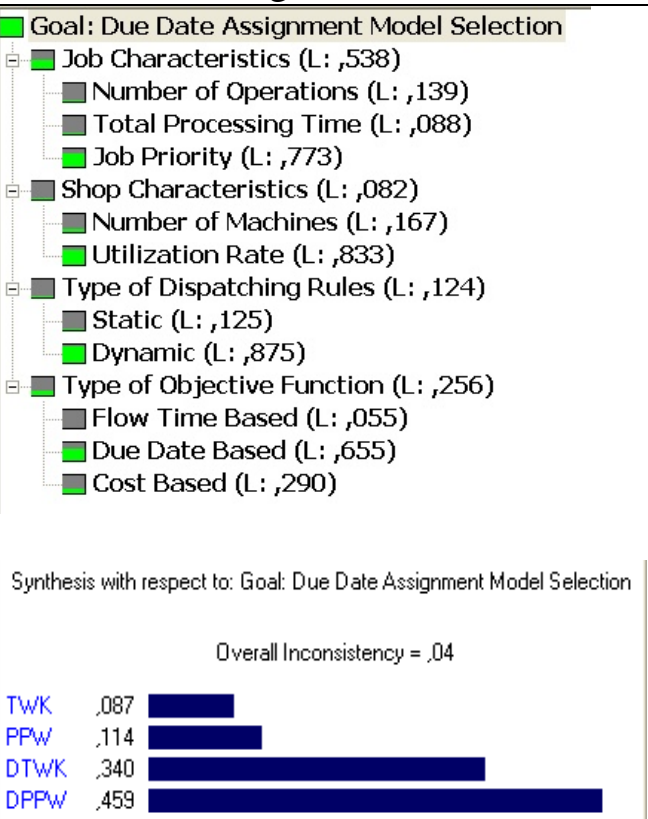

\section{Limitations}

As mentioned above, although grouping jobs into a few groups according to decision maker selected criterion/criteria may reduce the number of repeating the decision processes based on the AHP model, what is ideal is to run the AHP based decision process for selecting the most appropriate due date assignment model for each job before releasing to the shop without grouping but it is not practical. Besides, if the number of available due date assignment models as the alternatives is high for a group of jobs, the decision maker should reduce it to use the AHP model.

\section{Conclusions}

In this study, a solution methodology for determining the most appropriate due date assignment models for the jobs to optimize the aimed objective function by considering the related decision factors in a dynamic job shop environments is presented. There are many studies in the literature related to due date assignment models in a dynamic manufacturing environment but they almost all consider only one of the due date assignment models and that model is used to assign the due dates for all jobs arrived to the shop. There is no study which groups the jobs and assumes the different due date assignment models can be used to assign the due dates for each group of jobs. And also there is no study in the literature proposes an AHP/ANP model to prioritize the due date assignment models which are available for each group of jobs based on the many related decision factors. So this study will fill in that gap. One further study may be on 
IJAHP Article: Mu, Saaty/A Style Guide for Paper Proposals To Be Submitted to the International Symposium of the Analytic Hierarchy Process 2014, Washington D.C., U.S.A.

combining of dynamic determining of due date assignment models and dynamic selection of dispatching rules.

\section{Key References}

Chang, F.C.R., 1994. A study of factors affecting due date predictability in a simulated dynamic job shop. Journal of Manufacturing Systems, 13 (6), 393-400.

Pearn, W.L., Chung, S.H., Lai, C.M., 2007, Due-date assignment for wafer fabrication under demand variate environment, IEEE Transactıons on Semiconductor Manufacturing, 20 (2), 165-175

Joseph, O. A., Sridharan, R., 2011, Analysis of dynamic due-date assignment models in a flexible manufacturing system, Journal Of Manufacturing Systems, 30 (1), 28-40

Eguchi, T., Nishi, K., Kawai, H., 2012, Job Shop Scheduling To Meet Due Dates With Consideration To Sequence Dependent Setup Times In A Dynamic Environment, Proceedings Of The Asme/Iscie International Symposium On Flexible Automation, Isfa 2012, 365-368

Chen, B., Matis, T.I., 2013, A flexible dispatching rule for minimizing tardiness in job shop scheduling, International Journal Of Production Economics, 141(1), 360-365

Nguyen, S., Zhang, M., Johnston, M., Tan, K.C., 2014, Genetic Programming for Evolving Due-Date Assignment Models in Job Shop Environments, Evolutionary Computation, 22(1), 105-138

Buyurgan, N., Saygin, C., 2008, Application Of The Analytical Hierarchy Process For Real-Time Scheduling And Part Routing in Advanced Manufacturing Systems, Journal Of Manufacturing Systems, 27(3), 101-110

Yazgan, H.R., 2011, Selection of dispatching rules with fuzzy ANP approach, International Journal Of Advanced Manufacturing Technology, 52(5-8), 651-667

Cheng, T.C.E. and Jiang, J., 1998. Job shop scheduling for missed due dates performance. Computers and Industrial Engineering, 34 (2), 297-307. 